\title{
ANALISIS DAN PERBANDINGAN DATA SPEKTRUM UV, IR, DAN NMR TERHADAP STRUKTUR SENYAWA SKOPOLETIN
}

\author{
Tiara Aliqa*, Cut Laila Safrida, Megasari Lumban Batu, Hamidah \\ Nasution, Eliana, Zakirah Safrina, Siti Azizah, Rahayul Hayanum, \\ Siti Nurul Aini, Richa Arbina, dan Pera Mustika \\ Program Studi Pendidikan Kimia, FKIP Universitas Samudra \\ Jln. Kampus Meurandeh, Langsa 24416 \\ *Email: tiaraaliqa271@gmail.com
}

\begin{abstract}
Abstrak
Skopoletin adalah senyawa fenolik yang digolongkan kedalam senyawa kumarin dan secara sintesis dikenal sebagai (7-hidroksi-6-metoksi kumarin) yang ditemukan pada spesies tanaman yang berbeda. Adapun tujuan dari review jurnal ini yaitu untuk menganalisis dan membandingkan data spektrum UV, IR, dan NMR terhadap struktur senyawa skopoletin. Dari hasil analisis data yang telah dilakukan, spektrum UV memiliki kisaran panjang gelombang sebesar $245 \mathrm{~nm}$ dan $391 \mathrm{~nm}$. Struktur skopoletin yang ditetapkan berdasarkan spektrum IR dan NMR tersusun dari beberapa gugus fungsi diantaranya, 2 buah cincin benzena, gugus keton, hidroksi, eter, dan rangkap alkena.
\end{abstract}

Kata kunci : Skopoletin, spektrum, analisis

\section{Abstract}

Scopoletin is a phenolic compound that belongs to the coumarin compounds and is known synthetically as (7-hydroxy-6-methoxy coumarin) which is found in different plant species. The purpose of this journal review is to analyze and compare UV, IR, and NMR spectral data on the structure of scopoletin compounds. From the results of data analysis that has been carried out, the $U V$ spectrum has a wavelength range of $245 \mathrm{~nm}$ and $391 \mathrm{~nm}$. The structure of scopoletin determined based on the IR and NMR spectra is composed of several functional groups including 2 benzene rings, a ketone group, a hydroxy, an ether, and a double alkene.

Key words: Scopoletin, spectrum, analysis

\section{PENDAHULUAN}

Indonesia merupakan negara kedua yang memiliki keanekaragaman hayati terbanyak. Keanekaragaman hayati hutan tropis Indonesia merupakan sumber dari campuran alam yang khas, seperti limonoid, triterpenoid, seskuiterpenoid, steroid, seperti halnya fenolik yang struktur molekulnya bermacam-macam dan menunjukkan bioaktivitas yang menarik. Kumarin, termasuk campuran umum dan kerangka produksi yang fleksibel, berperan penting dalam industri farmasi. Sebagian besar kumarin dan turnannya menunjukkan berbagai aktivitas biologis dan farmakologis yang berbeda, misalnya antikanker, antiinflamasi, antioksidan, antidepresan, anti HIV, dan sebagainya (Shi et al., 2017).
Skopoletin adalah kumarin fenolik yang didapat dari jalur fenilpropanoid dan dapat diisolasi dari tumbuhan yang berbeda (Firmansyah et al., 2021), senyawa ini dikenal sebagai senyawa penting dari kelompok fitoaleksin. Ini memiliki struktur kristal kuning dengan berat molekul 192 dan titik leleh 204$206^{\circ} \mathrm{C}$ (Napiroon et al., 2018). Skopoletin diklasifikasikan sebagai kumarin dan secara sintetis dikenal (7-hidroksi-6metoksi kumarin) $\mathrm{C}_{10} \mathrm{H}_{8} \mathrm{O}_{4}$ fenolik kumarin yang ditemukan di berbagai spesies tanaman obat, misalnya Erycibe obtusifolia, Aster tataricus dan Foeniculum vulgare (Sampaio et al., 2021). Obat yang mengandung skopoletin diposisikan ketujuh belas sebagai obat untuk sel A 549 dan posisi 22 untuk sel $\mathrm{H}$ 260: penanda 
kerusakan sel di paru-paru (Aldi, Amdani, \& Bakhtiar, 2016).

$$
\text { Hasil penelitian menunjukkan }
$$

bahwa ada banyak tanaman yang mengandung senyawa skopoletin, antara lain yaitu pada buah mengkudu (Rini Prastiwi, Siska, 2017); ubi jalar (Aminah, Isma, \& Kristanti, 2019); ubi kayu (Silitonga, S.Si et al., 2019); tanaman kulit batang Dysoxylum parasiticum (Mayanti et al., 2017); dan tanaman subang-subang (Suryati, Efdi, Astuti, \& Aziz, 2016). Ubi jalar dengan nama latin Ipomoea batatas $L$. merupakan tanaman yang mengandung senyawa metabolit sekunder dan memiliki berbagai keunggulan, salah satunya adalah golongan fenolik ubi, yang merupakan kumpulan senyawa fenolik. Kandungan fenolik yang ditemukan dalam ubi jalar termasuk campuran kelompok fenil propanoid, flavonoid, dan lignan. Intensitas fenilpropanoid yang sering ditemukan adalah sinamat dan kumarin(Aminah et al., 2019).

Tanaman kulit batang Dysoxylum parasiticum (Meliaceae) diisolasi untuk menghasilkan senyawa flavanoid, kuersetin dan fenolik hingga skopoletin (Mayanti et al., 2017). Tanaman kulit batang Chisocheton cumingianus (Meliaceae) senyawa skopoletin menggunakan metode maserasi menggunakan n-heksana, asam asetat, dan metanol yang kemudian difokuskan untuk mendapatkan konsentrasi pekat (Amalya, Julaeha, Huspa, \& Maharani, 2020). Penulisan ini bertujuan untuk menentuan panjang gelombang maksimum dan absorbansinya dengan menggunakan spektroskopi UV (Aiman, Nirwana, \& Firdaus, 2019). Sedangkan penentuan struktur senyawa skopoletin dapat diidentifikasi melalui spektrum IR, dan NMR.

\section{METODE PENELITIAN}

Desain penelitian ini adalah Literatur Review (tinjauan pustaka). penelitian Literatur Review yaitu penelitian yang mengkaji secara kritis mengenai pengetahuan, gagasan, dan temuan yang ada dalam literatur. Adapun sifat dari penelitian ini adalah analisis deskriptif yaitu penguraian data yang sudah didapatkan yang selanjutnya diberika pemahaman dan penjelasan agar bisa dipahami dengan baik oleh pembaca.

Dalam penelitian ini terdapat kriteria inklusi dan ekslusi. Kriteria inklusi yaitu mengenai jangka waktu jurnal yang diteliti, subyek, bahasa, jenis junal, dan tema isi. Sedangkan kriteria ekslusi yaitu tipe studi, tipe intervensi, strategi pencarian literatur, dan hasil ukur. Berdasarkan kriteria dari inklusi dan ekslusi diperoleh hasil sebagai berikut

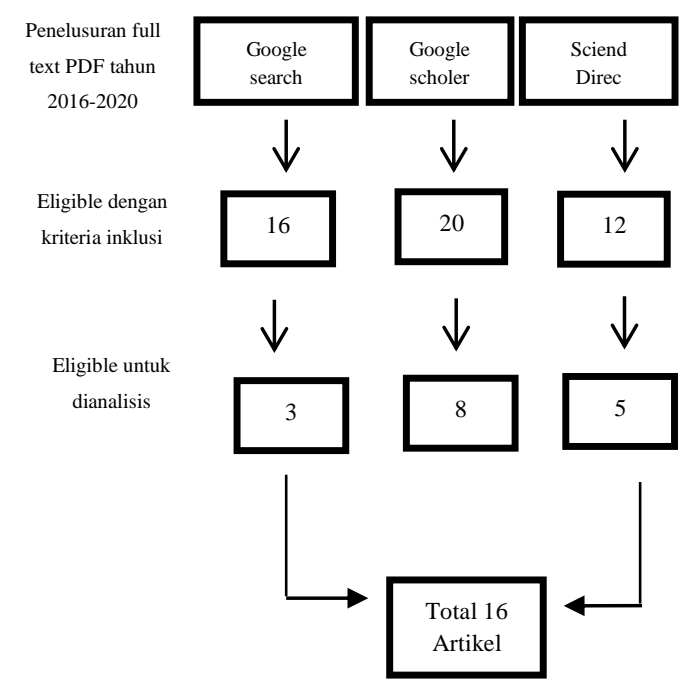

Gambar 1. Diagram Litetarur

Literatur Review ini diperoleh dengan menggunakan metode naratif yang menyatukandata-data hasil spektrum UV, IR, dan NMR pada senyawa skopolein sesuai dengan hasil yang diukur untuk menjawab tujuan. Jurnal penelitian yang temasuk dalam kriteria inklusi dikumpulkan dan diringkas dengan mencakup nama peneliti, tahun terbit jurnal, judul penelitian, metode dan ringkasan hasil penelitian.

Untuk mendapatkan hasil analisis yang baik, abstrak dan full text dari jurnal harus dibaca dengan cermat. Selanjutnya hasil ringkasan jurnal di analisis isi yang terdapat dalam tujuan penelitian dan hasil penelitian. Selasai dilakukan analisis 
jurnal,kemudian isi jurnal yang telah direview dilakukan pengkodean berdasarkan inti penelitian tersebut dengan menguraikan ke dalam kalimat. Selanjutnya di lihat persamaan atau perbedaan dari masing-masing penelitian melalui jurnal yang telah dianalisis agar dapat ditarik kesimpulan dari keseluruhan jurnal yang direview.

\section{HASIL DAN PEMBAHASAN}

Skopoletin adalah kumarin fenolik yang didapat dari jalur fenilpropanoid dan dapat diisolasi dari berbagai tanaman, misalnya ubi jalar, buah mengkudu dan tanaman subang-subang. Skopoletin dapat dipisahkan dari berbagai bagian tanaman (akar, buah, daun, batang, dan lain sebagainya) misalnya ubi jalar dengan nama latin Ipomoea batatas $L$. kulit batang Dysoxylum parasiticum (Meliaceae) dan kulit batang Chisocheton cumingianus (Meliaceae). Identifikasi struktur senyawa skopoletin dapat diperoleh melalui spektofotometri UV, spektroskopi IR, dan spektroskopi NMR.

Pada tabel 1 terdapat data-data panjang gelombang yang diperoleh dari sinar uv yang telah didapatkan dari penelitian sebelumnya. Perbandingan yang dilakukan agar dapat mendapatkan ratarata nilai panjang gelombang yang diperoleh pada proses identifikasi senyawa skopoletin.

Tabel 1. Perbandingan data spektrum UV skopoletin

\begin{tabular}{ll}
$\frac{\text { skopoletin }}{\lambda_{\text {maks }}}$ \\
\hline (Aminah, et al, 2019) & (Pramitha et al., 2016) \\
\hline $346,0 \mathrm{~nm}$ dan 297,0 $\mathrm{nm}$ & $241,5 \mathrm{~nm}$ dan $392 \mathrm{~nm}$
\end{tabular}

Keterangan : Aminah, et al, $2019=$ Penelitian 1 Pramitha et al., $2016=$ Penelitian 2

Pada penelitian 1 telah melakukan identifikasi mengenai skopoletin dengan menggunakan spektrum UV. Hasil $\lambda_{\text {maks }}$ penelitian yang telah dilakukan, menunjukkan panjang gelombang maksimum 388,50 nm dan $229 \mathrm{~nm}$. Dari hasil yang diperoleh, dapat dilihat bahwa skopoletin memiliki karakteristik yang sama dengan senyawa kumarin dan turunannya. Pengukuran dengan penambahan pereaksi $\mathrm{NaOH}$ dilakukan untuk mengetahui adanya gugus hidroksi yang terikat pada maks yang dihasilkan dari spektrum UV adalah $\lambda_{\text {maks }}$ benzena. Nilai panjang gelombang $346,0 \mathrm{~nm}$ dan 297,0 $\mathrm{nm}$.

Pada penelitian 2 analisis spektrum UV, mengindikasikan adanya struktur kumarin. Setelah penambahan $\mathrm{NaOH}$, terjadi pergeseran batokromik dari $\lambda_{\text {maks }}$ $230 \mathrm{~nm}$ menjadi $241,5 \mathrm{~nm}$ dan $\lambda_{\text {maks }} 345,5$ nm menjadi $392 \mathrm{~nm}$. Adanya pergeseran serapan maksimum menuju ke panjang gelombang yang lebih besar, menunjukkan bahwa terdapat gugus hidroksi yang terikat pada cincin aromatik.

Skolopetin memiliki serapan dalam panjang gelombang $245 \mathrm{~nm}$ dan $391 \mathrm{~nm}$ (Jain \& Joshi, 2012). Berdasarkan data (Suryati et al.,2016 dan Pramitha et al., 2016), panjang gelombang yang diperoleh tidak memiliki perbedaan yang signifikan. Sehingga dapat diasumsikan bahwa kisaran panjang gelombang yang dihasilkan membuktikan adanya senyawa kumarin yang tergolong dalam kelas skolopetin.

Pengukuran serapan merah inframerah (IR) dilakukan dengan lempeng $\mathrm{KBr}$ menggunakan alat FTIR Shimadzu 8400 (Mayanti et al., 2017). Metode spektroskopi IR menggunakan Perkin Elmer Spectrum 100 lempeng $\mathrm{KBr}$ (Nurlelasari, 2020). Data yang didapatkan dari kedua literatur tersebut tidak ada perbedaan yaitu skopoletin diperoleh sebagai padatan berwarna kuning. Adanya gugus $\mathrm{OH}\left(3340 \mathrm{~cm}^{-1}\right)$, regang $\mathrm{C}-\mathrm{O}$ ester dan $\mathrm{C}=\mathrm{O} \quad(1292 ; 1705) \quad \mathrm{cm}^{-1}$ yang mengidentifikasi adanya ester siklik (lakton) beranggota enam. Regang $\mathrm{C}=\mathrm{C}$ aromatik $\left(1567 \mathrm{~cm}^{-1}\right)$ dan lentur C-H ke luar bidang dari cincin aromatik $\left(1141 \mathrm{~cm}^{-}\right.$ $\left.{ }^{1}\right)$. Dari hasil perbandingan data dipeoleh bahwa panjang gelombang yang dihasilkan sesuai dengan nilai panjang gelombang 
pada renggangan dari gugus fungsi pembentukan senyawa skopoletin.<smiles>COc1cc2ccc(=O)oc2cc1O</smiles>

Gambar 2. Struktur Skopoletin

(Sumber: Aminah et al., 2019) sedang berputar di dalam medan magnet yang kuat, sangat berguna untuk mengidentifikasi struktur senyawa maka oleh sebab itu disini dilakukannya perbandingan antar literatur yang telah membahas senyawa skopoletin sebelumnya agar dapat melihat rata-rata data yang diperoleh dari spektrum ${ }^{1} \mathrm{H}$ NMR dan ${ }^{13} \mathrm{C}-\mathrm{NMR}$ pada senyawa skopolein (7-hidroksi-6-metoksi kumarin) yang telah tertera pada tabel 1 dan tabel 2 .

Metode spektroskopi didasarkan pada penyerapan energi oleh partikel yang

Tabel 2. Perbandingan data ${ }^{1} \mathrm{H}-\mathrm{NMR}$ skopoletin

\begin{tabular}{|c|c|c|c|}
\hline $\mathrm{C}$ & (Mayanti et al., 2017) & $\begin{array}{c}\delta \mathrm{H}(\text { mult, J) ppm } \\
\text { (Nurlelasari, 2020) }\end{array}$ & (Aminah et al., 2019) \\
\hline 2 & - & - & \\
\hline 3 & $7,84(\mathrm{~d}, 9,75 \mathrm{~Hz})$ & $7,36(\mathrm{~d}, 10 \mathrm{~Hz})$ & $7,82(\mathrm{~d}, 9,5 \mathrm{~Hz})$ \\
\hline 4 & $6,17(\mathrm{~d}, 9,75 \mathrm{~Hz})$ & $6,25(\mathrm{~d}, 10 \mathrm{~Hz})$ & $6,15(\mathrm{~d}, 9,5 \mathrm{~Hz})$ \\
\hline 5 & $6,79(\mathrm{~s})$ & $6,90(\mathrm{~s})$ & $7,16(\mathrm{~s})$ \\
\hline 6 & - & - & - \\
\hline 7 & - & - & - \\
\hline 8 & $7,19(\mathrm{~s})$ & $6,83(\mathrm{~s})$ & $6,77(\mathrm{~s})$ \\
\hline 9 & - & - & - \\
\hline 10 & - & - & - \\
\hline$-\mathrm{OCH}_{3}$ & $3,84(\mathrm{~s})$ & $3,93(\mathrm{~s})$ & $3,88(\mathrm{~s})$ \\
\hline Keterangan : & $\begin{array}{l}\text { Mayanti et al, } 2017= \\
\text { Nurlelasari, } 2020 \\
\text { Aminah, et al, } 2019\end{array}$ & & \\
\hline
\end{tabular}

Pada penelitian 1 , spektrum ${ }^{1} \mathrm{H}-$ NMR terlihat bahwa terdapat sepuluh isolat serta memiliki tujun proton dimana dari tiga proton dari sebuah gugus metoksi $\left(\delta_{\mathrm{H}} 3,84 \mathrm{ppm}\right.$, singlet $)$, dua proton olifenik pada $\mathrm{H}-4\left(\delta_{\mathrm{H}} 6,17 \mathrm{ppm}, 1 \mathrm{H}, d, \mathrm{~J}=9,75\right), \mathrm{H}-3$ $\left(\delta_{\mathrm{H}} 7,84 \mathrm{ppm}, 1 \mathrm{H}, d, \mathrm{~J}=9,75 \mathrm{~Hz}\right)$. pada data tersebut terdapat sinyal doublet dengan nilai terapan kompling $9,75 \mathrm{~Hz}$ yang merupakan salah satu ciri khas dari proton visinal yang berorentasi cis. Kemudian terdapat dua proton aromatik yang ditampakkan pada $\mathrm{H}-5\left(\delta_{\mathrm{H}} 6,79 \mathrm{ppm}, 1 \mathrm{H}\right.$, $d$, s) dan $\mathrm{H}-8\left(\delta_{\mathrm{H}} 7,19 \mathrm{ppm}, 1 \mathrm{H}, d, \mathrm{~s}\right)$ (Mayanti et al., 2017).

Pada penelitian 2, terlihat adanya keberadaan gugus metoksi yang dilihat dari terdapat sinyal singlet (s) proton $\delta_{\mathrm{H}}$ $3,93 \mathrm{ppm}$. Terdapat dua sinyal proton olifenik pada $\mathrm{H}-4 \delta_{\mathrm{H}} 6,25(\mathrm{~d}, 10 \mathrm{~Hz})$ dan $\mathrm{H}-\delta_{\mathrm{H}} 7,36(\mathrm{~d}, 10 \mathrm{~Hz})$ ppm. Kemudian adanya dua sinyal singlet (s) proton $\mathrm{H}-5 \delta_{\mathrm{H}}$
6,90 ppm (s) dan $\mathrm{H}-8$ 6,83 ppm (s)(Nurlelasari et al., 2020).

Pada penelitian 3, terdapat data spektrum ${ }^{1} \mathrm{H}-\mathrm{NMR}$ yang memperlihatkan adanya dua sinyal doublet pada proton $\mathrm{H}-3$ dan $\mathrm{H}-4(\mathrm{~J}=9,5 \mathrm{~Hz}) \delta_{\mathrm{H}} 6,15$ dan $\delta_{\mathrm{H}} 7,82$ ppm yang merupakan proton olifinik geometri cis. Terdapat dua sinyal singlet sekitar aromatik $\delta_{\mathrm{H}} 6,77$ dan $\delta_{\mathrm{H}}$ 7,16 ppm melihatkan bahwa adanya proton aromatik pada posisi para. Terlihat juga timbulnya sinyal dari subtituen metoksi dengan sinyal singlet $\delta_{\mathrm{H}} 3,88$ ppm(Aminah et al., 2019).

Maka terlihat dari data-data isolat senyawa skopoletin spektrum ${ }^{1} \mathrm{H}-\mathrm{NMR}$ dari beberapa literatur tersebut, setiap proton yang teridentifikasi tidak adanya perbedaaan yang terlalu signifikan baik geseran kimia, sinyal proton maupun nilai kompling dimana masing-masing data tersebut tergambarnya ciri-ciri dari diantaranya yaitu gugus metoksi, proton aromatik dan proton olefinik. 
Tabel 3. Perbandingan data ${ }^{13} \mathrm{C}-\mathrm{NMR}$ skopoletin

\begin{tabular}{|c|c|c|c|}
\hline $\mathrm{C}$ & (Mayanti et al., 2017) & $\begin{array}{c}\delta \mathrm{C} / \mathrm{ppm} \\
\text { (Nurlelasari et al.,2020) }\end{array}$ & (Aminah et al., 2019) \\
\hline 2 & 162,7 & 161,6 & 161,3 \\
\hline 3 & 144,7 & 143,4 & 113,2 \\
\hline 4 & 113,3 & 113,5 & 144,6 \\
\hline 5 & 109,9 & 107,5 & 110,0 \\
\hline 6 & 145,9 & 144,1 & 146,0 \\
\hline 7 & 151,8 & 150,3 & 112,0 \\
\hline 8 & 103,7 & 103,3 & 151,9 \\
\hline 9 & 151,2 & 149,8 & 103,7 \\
\hline 10 & 112,1 & 111,6 & 151,1 \\
\hline$-\mathrm{OCH}_{3}$ & 56,7 & 56,5 & 56,7 \\
\hline Keterangan : & $\begin{array}{l}\text { Mayanti et al, } 2017= \\
\text { Nurlelasari, } 2020 \\
\text { Aminah, et al, } 2019\end{array}$ & & \\
\hline
\end{tabular}

Dari penelitian 1 setelah diamati spektrum ${ }^{13} \mathrm{C}$-NMR adanya sepuluh sinyal karbon. Data terdapat dari enam karbon aromatik, satu karbonil ester dan dua karbon olifenik dan sebuah karbon teroksigenasi. Dua karbon olifenik teramati pada C-4 dan C-3 yaitu $\delta_{\mathrm{C}} 113,3$ dan 144,7, enam karbon aromatik teramati pada C-8 , C-5, C-10, C-6, C-7 dan C-9 yang terdiri dari $\delta_{C} 103,7 ; 109,9 ; 112,1$; 145,$9 ; 151,8$; dan 151,2 ppm. Satu buah karbonil ester terlihat pada C-2 $\delta_{\mathrm{C}} 162,7$ ppm dan karbon teroksigenasi teramati pada $\delta_{\mathrm{C}} 56,7 \mathrm{ppm}$.

Data dari penelitian 2, terlihat adanya sinyal dari aromatik pada spektrum ${ }^{13} \mathrm{C}$-NMR yang diperinci oleh DEPT $135^{\circ}$ menunjukkan sepuluh sinyal karbon yang terdiri dari empat karbon metin $\mathrm{sp}^{2}\left(\delta_{\mathrm{C}}\right.$ $103,3 ; 107,5 ; 113,5 ; 143,4)$. Lima karbon kuartener yang terdiri dari satu karbon $\mathrm{sp}^{2}$ $\left(\delta_{\mathrm{C}} 111,6\right)$. Serta tiga karbon kuartener teroksigenasi $\left(\delta_{\mathrm{C}} 144,1 ; 149,8 ; 150,3\right)$ ppm, satu karbonil ester $\left(\delta_{C} 161,6\right)$, dan satu sinyal metil teroksigenasi $\left(\delta_{\mathrm{C}} 56,3\right)$. Pada (Aminah et al., 2019) telah menganalisis spektrum ${ }^{13} \mathrm{C}$-NMR muncul sinyal karbon kuartener pada pergeseran

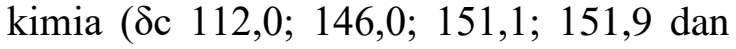
$161,3 \mathrm{ppm})$. Sinyal karbon metin pada pergeseran kimia $(\delta \mathrm{c} 103,7 ; 110,0 ; 113,2$; dan 144,6 ppm). Sinyal karbon metoksi pada daerah $\delta$ c 56,7 ppm(Nurlelasari, 2020).

Berdasarkan perbandingan data
${ }^{13} \mathrm{C}-\mathrm{NMR}$ diatas terdapat adanya

kecocokan yang cukup tinggi antara pergeseran kimianya. Serta tidak adanya perbedaan yang terlalu jauh antar nilai geseran kimia yang diperoleh. Maka dengan adanya data-data tersebut akan memudahkan para peneliti melalukan penelitian kedepannya, dikarenakan sudah adanya panduan data spektrum ${ }^{1} \mathrm{H}$ NMRdan ${ }^{13} \mathrm{C}$-NMR yang telah didapatkan penelitian sebelumnya.

\section{KESIMPULAN}

Skopoletin merupakan senyawa fenolik yang digolongkan ke dalam senyawa kumarin dan secara sintesis dikenal sebagai (7-hidroksi-6-metoksi kumarin) yang ditemukan pada spesies tanaman yang berbeda. Dari hasil perbandingan data spektrum UV, IR dan NMR dari beberapa literatrur sehingga mendapatkan hasil yang tidak ada perbedaan yang signifikan antar data yang diperoleh oleh peneliti yang berbeda. Sehingga dari kumpulan data-data tersebut maka disimpulkan bahwa struktur senyawa skopoletin tersusun dari beberapa gugus fungsi diantaranya, 2 buah cincin benzena, gugus keton, hidroksi, eter, dan rangkap alkena.

\section{DAFTAR PUSTAKA}

Aiman, U., Nirwana, N., dan Firdaus, M. L. 2019. Peningkatan Hasil Belajar Siswa dengan Menerapkan Video Identifikasi Campuran Kopi Menggunakan Metode Spektroskopi UV-Visible. PENDIPA Journal of 
Science Education, 3(1), 1-7.

Aldi, Y., Amdani, A., dan Bakhtiar, A. 2016. Aktivitas Senyawa Skopoletin dari Buah Mengkudu (Morinda citrifolia, Linn) Terhadap Respon Fisiologi Makrofag Mencit Putih Jantan. Scientia : Jurnal Farmasi dan Kesehatan, 6(1), 25.

Amalya, T. P., Julaeha, E., Huspa, D. H. P., dan Maharani, R. 2020. Chimica et Natura Acta. 8(2), 68-71.

Aminah, N. S., Isma, C., dan Kristanti, A. N. 2019. Skopoletin Suatu Senyawa Fenilpropanoid Dari Ekstrak Etil Asetat Umbi Ubi Jalar (Ipomoea batatas L.). Jurnal Kimia Riset, 3(2), 116.

Pramitha, Citra Putri ., Kristanti, Alfinda Novi dan N. S. A. 2016. SkopoletinSenyawa Fenilpropanoid Dari Kulit Umbi Ubi Jalar (Ipomoea Batatas L.) Varietas IR-Melati. Journal Kimia Riset, 1(2), 951-952.

Firmansyah, A., Winingsih, W., dan Manobi, J. D. Y. 2021. Review of scopoletin: Isolation, analysis process, and pharmacological activity. Biointerface Research in Applied Chemistry, 11(4), 1200612019.

Jain, P. K., dan Joshi, H. 2012. Coumarin: Chemical and pharmacological profile. Journal of Applied Pharmaceutical Science, 2(6), 236240.

Mayanti, T., Wahyuni, A., Indriyani, I., Darwati, D., Herlina, T., dan Supratman, U. 2017. SenyawaSenyawa Aromatik dari Ekstrak Daun dan Kulit Batang Dysoxylum parasiticum Serta Toksisitasnya Terhadap Artemia salina. Chimica et Natura Acta, 5(1), 26.
Mayanti, T., Wahyuni, A., Indriyani, I., Herlina, T., dan Supratman, U. 2017. Chimica et Natura Acta. 5(1), 26-30.

Napiroon, T., Bacher, M., Balslev, H., Tawaitakham, K., Santimaleeworagun , W., dan Vajrodaya, S. 2018. Scopoletin from Lasianthus lucidus Blume (Rubiaceae): A potential antimicrobial against multidrugresistant Pseudomonas aeruginosa. Journal of Applied Pharmaceutical Science, 8(9), 1-6.

Nurlelasari, T.P., Amalya, E., Julaeha, D., Harneti. Huspa, R., Maharani, dan Darwati, U., S. 2020. 7-hidroksi-6metoksi Kumarin (Skopoletin) dari Ekstrak Metanol Kulit Batang Chisocheton cumingianus (Meliaceae). Chimica et Natura Acta, 6(2), 93-100.

Rini Prastiwi, dan Siska, N. O. 2017. Parameter Fisikokimia Dan Penetapan Kadar Scopoletin Pada Ekstrak Etanol $70 \%$ Buah Mengkudu (Morinda citrifolia L.) dengan Perbandingan Daerah Tempat Tumbuh. Prosiding Seminar Nasional, 97-106.

Sampaio, P. A., Serafim, S. C., Nascimento Menezes, P. M., Valença Pereira, E. C., Sousa de Sá, P. G., Texeira de Alencar Filho, dan J. M., ... Rolim, L. A. 2021. Development and characterization of the zeolite imidazolate framework for a modified release of the drug scopoletin. Journal of Drug Delivery Science and Technology, 61(September).

Shi, W., Hu, J., Bao, N., Li, D., Chen, L., dan Sun, J. 2017. Design, synthesis and cytotoxic activities of scopoletinisoxazole and scopoletin-pyrazole hybrids. Bioorganic and Medicinal Chemistry Letters, 27(2), 147-151. 
Silitonga, S.Si, R. F., Hasanah, F., Hasrini, R. F., Nugroho, A. F., Wijaya, H., dan Siswawati, I. K. 2019. Identifikasi Skopoletin pada Ubi Kayu (Manihot esculenta C.) Sebagai Bahan Baku Industri Tapioka di Lampung. Warta Industri Hasil Pertanian, 36(1), 56.

Suryati, Efdi, M., Astuti, S. H., \& Aziz, H. (2016). Isolation of scopoletin from subang-subang plants (Spilanthes paniculata Wall. ex DC.). Der Pharma Chemica, 8(9), 94-98. 